\title{
The effectiveness of combined bracing and exercise in adolescent idiopathic scoliosis based on SRS and SOSORT criteria: a prospective study
}

\author{
Stefano Negrini ${ }^{1,2^{*}}$, Sabrina Donzelli ${ }^{3}$, Monia Lusini ${ }^{3}$, Salvatore Minnella ${ }^{3}$ and Fabio Zaina ${ }^{3}$
}

\begin{abstract}
Background: Recently an RCT confirmed brace efficacy in adolescent idiopathic scoliosis (AIS) patients. Previously, a Cochrane review suggested also producing studies according to the Scoliosis Research Society (SRS) criteria on the effectiveness of bracing for AIS. Even if the SRS criteria propose a prospective design, until now only one out of 6 published studies was prospective. Our purpose was to evaluate the effects of bracing plus exercises following the SRS and the international Society on Scoliosis Orthopedic and Rehabilitation Treatment (SOSORT) criteria for AIS conservative treatment.
\end{abstract}

Methods: Study design/setting: prospective cohort study nested in a clinical database of all outpatients of a clinic specialized in scoliosis conservative treatment.

Patient sample: seventy-three patients ( 60 females), age 12 years 10 months \pm 17 months, $34.4 \pm 4.4$ Cobb degrees, who satisfied SRS criteria were included out of 3,883 patients at first evaluation.

Outcome measures: Cobb angle at the end of treatment according to SRS criteria : (unchanged; worsened $6^{\circ}$ or more, over $45^{\circ}$ and surgically treated, and rate of improvement of $6^{\circ}$ or more).

Braces were prescribed for 18-23 hours/day according to curves magnitude and actual international guidelines. Weaning was gradual after Risser 3. All patients performed exercises and were managed according to SOSORT criteria. Results in all patients were analyzed according to intent-to-treat at the end of the treatment. Funding and Conflict of Interest: no.

Results: Overall 34 patients (52.3\%) improved. Seven patients (9.6\%) worsened, of which 1 patient progressed beyond $45^{\circ}$ and was fused. Referred compliance was assessed during a mean period of 3 years 4 months \pm 20 months; the median adherence was 99.1\% (range 22.2-109.2\%). Employing intent-to-treat analysis, there were failures in 11 patients (15.1\%). At start, these patients had statistically significant low BMI and kyphosis, high thoracic rotation and higher Cobb angles. Drop-outs showed reduced compliance and years of treatment; their average scoliosis at discontinuation was low: $22.7^{\circ}$ (range $16-35^{\circ}$ ) at Risser $1.3 \pm 1$.

Conclusions: Bracing in patients with AIS who satisfy SRS criteria is effective. Combining bracing with exercise according to SOSORT criteria shows better results than the current literature.

Keywords: Adolescent Idiopathic Scoliosis, Bracing, Exercises

\footnotetext{
* Correspondence: stefano.negrini@unibs.it

'Department of Clinical and Experimental Sciences, University of Brescia,

Viale Europa 11 Brescia, Italy

${ }^{2}$ IRCCS Don Gnocchi Foundation, Milan, Italy

Full list of author information is available at the end of the article
} 


\section{Background}

Recently a multicenter RCT investigating the role of bracing in AIS patients at risk of curve progression, confirmed brace efficacy. The authors conclude that bracing significantly decreased the progression of high risk curves and that the longer the brace wear the best were the results [1].

Previously, a Cochrane review [2] favoured bracing in adolescent idiopathic scoliosis (AIS) treatment. The evidence was however based on a "very low quality" prospective observational cohort that found bracing to be more effective in reducing curve progression to surgery compared with observations only and electrical stimulation [3]. To increase this quality we would need randomized controlled trials (RCTs): nevertheless, RCTs either the last one by Weinstein [1], as the previously published, in the Netherlands [4-6], and in the US [7] failed, and had to be changed to observational [8], due to the difficulty in recruiting patients. Recently, results of an RCT on the SpineCor brace have been presented at the SOSORT Meeting (Coillard et al. [9]).

In 1995 the SRS proposed the methodological criteria for studies on brace effectiveness [10]. For inclusion: at least age 10 at brace prescription; Risser $0-2$; primary curve angles between $25^{\circ}$ and $40^{\circ}$; no previous treatment; if female, either premenarchal or less than 1 year postmenarchal. For outcome assessment: curve progression less than $6^{\circ}$ or more than $5^{\circ}$; curves exceeding 45 degrees at maturity; and surgery recommended/ undertaken. For the last criterion, a 2-year follow-up beyond maturity is required. Design should be prospective, and an intent to treat analysis should be performed, including all patients.

In 2008, the international Society On Scoliosis Orthopedic and Rehabilitation Treatment (SOSORT) proposed the criteria for management of braced patients in clinics and during research studies [11]. The SOSORT criteria include 14 recommendations, grouped in 6 Domains (Experience/ competence, Behaviours, Prescription, Construction, Brace Check, Follow-up). They mainly stress the importance of a good and expert conservative team surrounding the patient and family, to serve as a guarantee of quality of braces and increase compliance, that is a main determinant of final results [12-15].

In the already mentioned Cochrane review [2] it is suggested that, while waiting for RCTs results, studies according to the SRS (and SOSORT) criteria are tools to obtain evidence on the effectiveness of bracing for AIS. Today it is possible to find 5 studies respecting all these criteria [9,16-19]: looking at them as a whole, bracing seems to alter positively the natural history of AIS, and apparently best results can be achieved when the SOSORT criteria are satisfied [2].
Nevertheless, even if the SRS criteria propose to follow a prospective design, until now only one out of the 6 published studies respecting the SRS criteria was prospective [20]: this did not respect the SOSORT criteria. Such a design gives stronger evidence, since it allows to perform not only an efficacy analysis (results on patients who completed treatment), but also an intent-to-treat analysis (results on all treated patients) [10].

Aim of the present study was to evaluate the effects of a complete conservative treatment (bracing plus exercises) strictly following the SRS and SOSORT criteria.

\section{Methods}

\section{Study design}

We performed a cohort prospective study nested in a clinical database including all patients referred to our Institute (an outpatient clinic specialized in idiopathic scoliosis clinical evaluation and treatment, with patients coming from all over Country and abroad).

The prospective database from which data were extracted was started in March 2003, the target population was made by AIS patients at their first evaluation recruited into the database during the period comprised between march 2003 and the $31^{\text {st }}$ of July 2008 . The study has been performed on the $31^{\text {st }}$ of December 2011.

All patients gave an informed consent to their data management for clinical and research purposes. Since this study is based on the regular everyday clinical activity of our Institute, an Ethical Committee approval was not required.

\section{Population}

We strictly followed the SRS inclusion criteria [10]. The process of extraction is synthesized in Figure 1, in which the number of patients progressively excluded are listed. We evaluated 3,883 patients; at start of the study, of which 148 patients respected the SRS criteria. Thirty-nine adolescents were excluded because they only came, to our institution, for second opinion consultation, and were not treated by us. Additionally, 36 patients were excluded because, at the end of the study, had not yet completed their treatments.

Finally, 73 patients (60 females - $82.2 \%$ - and 13 males $17.8 \%$ ) have been included. Average curves were $30.4 \pm$ 4.4 , with an average age of $12.10 \pm 1.05$ years. Thirty-nine (53.4\%) had single, 32 (43.8\%) double and $2(2.7 \%)$ had triple curves (Table 1). For the purposes of analysis, patients were also classified in terms of convexity of curves: typical curves being right thoracic, left thoracolumbar/ lumbar curves, and atypical ones being the opposite convexities (Table 1). 


Total of scoliosis patients in the database
SRS exclusion criteria
Secondary scoliosis
Previous treatment
Age at first evaluation below 10 or above 18 years
Risser stage above 2
Cobb degrees below $25^{\circ}$ or above $40^{\circ}$
Females more than 1 year post-menarche
Other reasons for exclusion
Still in treatment
Second opinion

\section{Methods}

All patients were proposed to be treated with braces and exercises. Braces were personalized by physicians according to individual needs:

- The Sibilla brace [21] was preferred in case of low rigidity and BMI, and reduced Cobb degrees: it was prescribed in $61.6 \%$ of included patients

- The Lyon [22] (before 2004-5) and Sforzesco [21] braces (from 2005) were preferred in cases of high rigidity and BMI, and severe Cobb degrees (over $35^{\circ}$ ): they were prescribed in $16.4 \%$ and $13.7 \%$ of cases respectively

- The SpineCor brace [23] was prescribed after 2008, only in cases below $30^{\circ}$ and low rigidity: it was used in $6.8 \%$ of cases.

At start of treatment, hours of brace use were personalized, and patients were grouped accordingly:

- Full time (22-23 hours per day - h/d): 30 patients,

- Part-time (16-18 h/d): 21 patients,

Table 1 Topographic classification of patients included in the study

\begin{tabular}{|c|c|c|c|c|c|c|}
\hline Type & $\%$ & Localization & $\%$ & Convexity & $\%$ & Type of curve \\
\hline \multirow[t]{6}{*}{ Single } & $53.42 \%$ & Thoracic & $16.44 \%$ & Right & $15.07 \%$ & Typical \\
\hline & & & & Left & $1.37 \%$ & Atypical \\
\hline & & Thoraco-lumbar & $21.92 \%$ & Right & $6.85 \%$ & Atypical \\
\hline & & & & left & $15 .() 7 \%$ & Atypical \\
\hline & & Lumbar & 15.07 & Right & $0.00 \%$ & Atypical \\
\hline & & & & left & $15.07 \%$ & Typical \\
\hline \multirow[t]{6}{*}{ Double } & $43.84 \%$ & Thoracic-Lumbar & $20.55 \%$ & Right-Left & $19.18 \%$ & Typical \\
\hline & & & & Left-Right & $1.37 \%$ & Atypical \\
\hline & & Thoracic Thoracolumbar & $17.81 \%$ & Right Left & $12.33 \%$ & Typical \\
\hline & & & & Left-Right & $5.48 \%$ & Atypical \\
\hline & & Double thoracic (proximal-distal) & $5.48 \%$ & Right-Left & $1.37 \%$ & Atypical \\
\hline & & & & Left-Right & $4.11 \%$ & Typical \\
\hline \multirow[t]{2}{*}{ Triple } & $2.74 \%$ & Double Thoracic-Thoracolumbar & $2.74 \%$ & Left-Right-Left & $2.74 \%$ & Typical \\
\hline & & & & Right Left Right & $0.00 \%$ & Atypical \\
\hline
\end{tabular}


- Intermediate (19-21 h/d): 22 patients.

Prescriptions were in agreement with international guidelines of AIS treatment and all the physiscian involved in the study were part of a team sharing all the treatment aim and therapeutical choices.

During the period of the study, the Thermobrace sensor was not used to measure the exact compliance, but we assumed similar results as those previously published [24].

The main rule observed during weaning was to avoid reducing hours of treatment below $18 \mathrm{~h} / \mathrm{d}$ before reaching Risser 3 stage. According to this rule, a 2 hours reduction every 6 months started since first follow-up visit (usually performed after 4 months), with two exceptions: worsening (no reduction) and first control visit in case of full time wearing (one hour reduction only). The combination of the two rules, drive to final weaning on average 2.5 years after Risser 3, generally corresponding to Risser 5. As already described [25], this gradual weaning is performed to allow an adaptation of the postural system that, combined with exercises performance, should increase the possibility of stabilization of best results obtained.

All patients were prescribed Physiotherapic Specific Exercises (PSE) [15]: 3 patients did not perform any exercise (NE), 35 followed usual physiotherapy (UP) and 35 came to our Institute to learn PSE according to the SEAS school [26], that proved to be able to reduce correction loss during brace weaning [27], and to increase correction at first brace wearing [28].

SOSORT management criteria were fully respected (43/ 44 criteria fulfilled, with one not applicable) [11].

\section{Outcome criteria}

End of treatment was defined as follows: indication by the treating physician and/or achievement of Risser 3 stage according to the European staging, corresponding to Risser 4 in the US $[29,30]$.

The SRS outcome criteria were followed [10]. These included percentage of patient unchanged (less than $6^{\circ}$ progression); worsened ( $6^{\circ}$ or more); over $45^{\circ}$ at the end of treatment; surgically treated. Since scoliosis can also be improved [25,31], we also added rate of improvement (defined as a reduction of $6^{\circ}$ or more). Moreover, radiographic and clinical data have been computed [25,32].

\section{Statistical analysis}

Conforming the SRS criteria [10], we performed an Intentto-treat analysis, where failures included patients that:

- Reached $45^{\circ}$ at the end-of-treatment;

- Were fused;

- Dropped-out (treatment stopped before reaching end-of-treatment) without any final radiographic evaluation;
- Dropped-out at Risser stage 0 or 1 ;

- Dropped-out at European Risser 2 (corresponding to US Risser 3) [29,30], only if the curve was of $35^{\circ}$ Cobb or more: in fact, at this stage the risk of fusion and/or progression to $45^{\circ}$ or more is negligible [10].

An Intent-to-treat analysis gives the overall usefulness of a treatment, but in many cases (such as that of braces) it is interesting also to know which results can be achieved in case patients decide to adhere to treatment: for this reason we performed also an efficacy analysis, looking only at patients who reached the end-of-treatment.

\section{Results}

Looking at the overall results (Table 2), 7 (9.6\%) patients worsened, 1 (1.4\%) progressed beyond $45^{\circ}$ and was the only one fused; 8 patients (11\%) dropped-out from the study before reaching the end-of-treatment.

Drop-outs (Table 3) concluded treatment after $17 \pm$ 7 months of treatment. In this group, four patients did not have a final $x$-ray, and consequently it was not possible to know if they had reached Risser 3 stage (end-oftreatment). Patients dropped-out who had final x-rays had on average $22.7^{\circ}$ (range 16-34 ${ }^{\circ}$ ) of scoliosis with a Risser stage 0 or 1 in 1 case each, and 2 in 4 cases.

According to the Intent-to-treat analysis (Table 2), failures were 11 (15.1\%); in terms of Efficacy analysis, out of the 63 patients who reached the end-of-treatment, 3 patients progressed (4.8\%), 1 reached $45^{\circ}$ and was fused (1.6\%). All subgroup analysis suggested by the SRS Committee [10] are listed in Table 4.

BMI was lower in failures than non-failures at start of treatment $(16.5 \pm 2.0$ vs $19.1 \pm 2.5)$. Clinical evaluation of kyphosis [33] and major thoracic ATR respectively were also lower in failures at start of treatment $(50.0 \pm 29.2$ vs $68.7 \pm 20.5), \quad(10.7 \pm 2.9$ vs $7.8 \pm 3.4)$. Cobb degrees showed stastically significant lower values in failures, too $(32.8 \pm 6.3$ vs $25.1 \pm 6.9)$. We did not find differences in terms of gender, type and hours of brace prescribed, and type of curve. In terms of treatment, failures showed reduced compliance to bracing $(88.2 \pm 14.5 \%$ vs $93.4 \pm$ $13.0 \%)$; moreover, usual physiotherapy or no exercises versus PSE were more frequent in failures than in successes (82\% vs $47 \%)$.

Finally, successes had statistically significant improvements in all parameters (Table 5); in failures there were no statistically significant differences with treatment (neither improvements or worsening).

\section{Discussion}

This cohort prospective study proves the efficacy of a complete conservative treatment of AIS, including bracing and exercises, in the high risk population proposed by the SRS criteria [10]. The Efficacy analysis showed 
Table 2 Results according to the two main analysis performed

\begin{tabular}{|c|c|c|c|c|c|c|c|c|c|c|c|c|c|c|c|c|c|}
\hline & \multicolumn{2}{|c|}{$\begin{array}{c}\text { Total } \\
\text { population }\end{array}$} & \multicolumn{3}{|c|}{ Improved } & \multicolumn{3}{|c|}{ Unchanged } & \multicolumn{3}{|c|}{ Worsened } & \multicolumn{3}{|c|}{ Over 450} & \multicolumn{3}{|c|}{ Failures (surgery) } \\
\hline & $\mathbf{N}$ & $\%$ & $\mathbf{N}$ & $\%$ & C195 & $\mathbf{N}$ & $\%$ & C195 & $\mathbf{N}$ & $\%$ & C195 & $\mathbf{N}$ & $\%$ & C195 & $\mathrm{N}$ & $\%$ & $\mathrm{Cl} 95$ \\
\hline Intent-to- treat analysis & 73 & $100 \%$ & 34 & $46.5 \%$ & $34.3-56.6 \%$ & 27 & $36.9 \%$ & $25.6-47.1 \%$ & 7 & $9.6 \%$ & $4.8-18.5 \%$ & 1 & $1.4 \%$ & $0.3-7.3 \%$ & 4 & $5.5 \%$ & $4.2-15.0 \%$ \\
\hline Efficacy analysis & 65 & $100 \%$ & 33 & $50.8 \%$ & $40.2-64.2 \%$ & 26 & $40.0 \%$ & 29.9-53.6\% & 4 & $6.2 \%$ & $2.6-15.2 \%$ & 1 & $1.5 \%$ & $0.4-8.4 \%$ & 1 & $1.5 \%$ & $0.4-8.4 \%$ \\
\hline
\end{tabular}

a percentage of fusions of $1.6 \%$, and of progression of $4.8 \%$.

Since 10 patients dropped from the study before ending treatment, the percentage of failures in the Intentto-treat analysis was $15.1 \%$ : even if this is the correct methodological approach, in clinical terms the real possibility that all these patients would have been in the end (or will ever be in their future) surgical is doubtful: in fact their average curvature was very far from the surgical threshold $\left(22.7^{\circ}\right.$; range $\left.16^{\circ}-34^{\circ}\right)$ with a low risk of progression bone age (Risser 2 in $66.6 \%$ of cases). This is the second prospective study respecting the SRS criteria [10]; since the first one was focused on the SpineCor brace [9], this is the first one focusing mainly on rigid braces. A main characteristic of this paper is that it focuses on a general conservative approach to conservative treatment, more than on specific braces. In fact, many different braces have been included, some developed by the authors according to their own correction concepts [21], others by different researchers following various concepts [22,23]. In this respect, the choice of different instruments have been made on an individual basis according to the expertise of the treating physicians.

When compared to other studies in the literature, this prospective paper shows very low surgical rates, comparable to some already presented in the past [9,17,31,34-36], but substantially different from others $[18,37]$. The main possible explanations of these results include the efficacy of the brace used $[2,13,38]$, the expertise in bracing

Table 3 Charactheristic of the patients that finished the study before end of treatment (physician prescription and/or Risser 3 stage) (drop-outs)

\begin{tabular}{lccc}
\hline Patient & Cobb degrees & Risser stage & Final result \\
\hline 1 & 35 & 2 & Failure \\
2 & 34 & 0 & Failure \\
3 & 28 & 2 & Success \\
4 & 24 & 2 & Success \\
5 & 20 & 2 & Success \\
6 & 20 & 0 & Failure \\
7 & 20 & 2 & Success \\
8 & 16 & 2 & Success \\
\hline
\end{tabular}

Definition of failure or success according to what reported in the text.
$[11,15]$, the management of patients possibly able to increase general compliance to treatment $[11,15,24]$ : in the perspective of the conservative experts of SOSORT $[11,15]$ all these points, resumed in the SOSORT criteria [11], should be respected.

Another key point confirmed by this study is the fact that AIS patients adequately treated can improve, and not only avoid progression. This possibility has been already carried forward in previous studies [9,17,25,31,34-36], and should be included as a possible outcome criterion, together with those proposed by the SRS [10].

Moreover it was possible to find some differences at baseline between failures and successes. These include characteristics well known as possibly negative prognostic factors, like low BMI, flat back and severe thoracic curve [15]. Nevertheless, these factors should be regarded very cautiously in this study, since failures mainly included drop-out, i.e. patients that did not complete treatment. Coherent with this point, is the low referred compliance in this group, and the performance of Usual Physiotherapy.

The main strength of this paper is the prospective design coming from a wide clinical database: this allowed to be very selective in the inclusion criteria: consequently the population is very coherent and representative. Moreover, this study represents the everyday clinical reality, and not an experimental set-up: this increases its ecological reliability. The main weaknesses are the observational design, and the absence of a control group: the last one was already considered by the SRS when it defined its inclusion criteria [10], that should represent the population at highest risk of progression. In this respect, this study can be very easily compared to the others with the same design [9,16-19], that in a way are comparable control groups. Some previously published papers strongly support the results of the current study in terms of the effectiveness of bracing, but the comparisons are limited by the lack of a complete respect to the SOSORT and SRS criteria $[39,40]$. This point of view justify the choice of a design of the study strictly respecting these criteria, which have been proposed only by consensus, but aim to make comparable the results obtained by different group of researchers.

The inclusion of different brace type and the association with exercise can be interpreted as a limitation of the study, because of the effects of confounders. However the scientific literature is not yet able to demonstrate what is 
Table 4 Subgroup analysis suggested by the SRS Committee

\begin{tabular}{|c|c|c|c|c|c|c|c|}
\hline & & Total population & Improved & Unchanged & Worsened & Over 45 & Surgery \\
\hline \multirow[t]{3}{*}{ Number of major curves } & Single & 38 & 22 & 14 & 2 & 0 & 0 \\
\hline & Double major & 32 & 13 & 15 & 2 & 1 & 1 \\
\hline & Triplemajor & 2 & 1 & 1 & 0 & 0 & 0 \\
\hline \multirow[t]{7}{*}{ Topographic classification } & Thoracic & 12 & 5 & 6 & 1 & 0 & 0 \\
\hline & Thoracolumbar & 16 & 12 & 4 & 0 & 0 & 0 \\
\hline & Lumbar & 10 & 5 & 4 & I & 0 & 0 \\
\hline & Thoracic-Lumbar & 16 & 6 & 7 & 1 & 1 & 1 \\
\hline & Thracic-Thoracolumbar & 13 & 6 & 6 & 1 & 0 & 0 \\
\hline & Double thoracic & 3 & 1 & 2 & 0 & 0 & 0 \\
\hline & Double thoracic- lumbar & 2 & 1 & 1 & 0 & 0 & 0 \\
\hline \multirow[t]{2}{*}{ Curvature type } & Typical & 61 & 32 & 23 & 4 & 1 & 1 \\
\hline & Atypical & 11 & 4 & 7 & 0 & 0 & 0 \\
\hline \multirow[t]{3}{*}{ Magnitude of curvature } & $25-30$ & 40 & 21 & 18 & 1 & 0 & 0 \\
\hline & $31-35$ & 20 & 8 & 10 & 2 & 0 & 0 \\
\hline & $36-40$ & 12 & 7 & 2 & 1 & 1 & 1 \\
\hline \multirow[t]{3}{*}{ Skeletal maturity } & Risser 0 & 48 & 23 & 21 & 2 & 1 & 1 \\
\hline & Risser 1 & 10 & 5 & 3 & 2 & 0 & 0 \\
\hline & Risser 2 & 14 & 8 & 6 & 0 & 0 & 0 \\
\hline \multirow[t]{3}{*}{ Brace } & Sibilla & 45 & 27 & 17 & 1 & 0 & 0 \\
\hline & Lyon/Sforzesco & 20 & 7 & 11 & 2 & 1 & 1 \\
\hline & SpineCor & 5 & 2 & 2 & 1 & 0 & 0 \\
\hline \multirow[t]{3}{*}{ Dosage of bracing } & Full-time & 30 & 12 & 15 & 3 & 1 & 1 \\
\hline & Intermediate & 21 & 12 & 9 & 0 & 0 & 0 \\
\hline & Part-time & 22 & 12 & 9 & 1 & 0 & 0 \\
\hline
\end{tabular}

Table 5 Clinical results

\begin{tabular}{|c|c|c|c|c|c|c|c|}
\hline & & \multicolumn{3}{|c|}{ Success } & \multicolumn{3}{|c|}{ Failure } \\
\hline & & Average & Standard deviation & $\mathbf{P}$ & Average & Standard deviation & $\mathbf{P}$ \\
\hline \multirow[t]{5}{*}{ Scoliosis curves (Cobb degrees) } & Thoracic & -3.89 & 6.26 & 0.0001 & 2.33 & 17.90 & NS \\
\hline & Thoracolumbar & -7.41 & 7.22 & 0.0001 & 5.00 & & \\
\hline & Lumbar & -6.67 & 6.79 & 0.0001 & -7.00 & 2.83 & NS \\
\hline & Maximum & -6.32 & 7.03 & 0.0001 & 0.00 & 15.77 & NS \\
\hline & Main curves & -6.37 & 7.36 & 0.0001 & 0.44 & 17.57 & NS \\
\hline \multirow[t]{3}{*}{ ATR (degrees) } & Thoracic & -2.73 & 2.34 & 0.0001 & -1.63 & 4.24 & NS \\
\hline & Thoracolumbar & -3.65 & 2.84 & 0.0001 & -7.50 & 3.54 & NS \\
\hline & Lumbar & -3.58 & 3.05 & 0.0001 & -4.50 & 0.71 & NS \\
\hline \multirow[t]{4}{*}{ Plumbline distances (mm) } & $\mathrm{C} 7$ & -7.90 & 11.82 & 0.0001 & 0.91 & 18.82 & NS \\
\hline & $\mathrm{T} 12$ & -8.15 & 31.00 & 0.0500 & -0.91 & 16.25 & NS \\
\hline & L3 & -2.98 & 13.92 & NS & 0.45 & 18.77 & NS \\
\hline & $\mathrm{C} 7+\mathrm{L} 3$ & -10.89 & 20.68 & 0.0001 & 1.36 & 27.21 & NS \\
\hline \multirow[t]{2}{*}{ Decompensation (mm) } & Lateral & -3.87 & 11.92 & 0.0500 & -5.45 & 14.40 & NS \\
\hline & Sagittal & 3.15 & 14.29 & NS & 2.73 & 13.30 & NS \\
\hline TRACE (points) & & -3.02 & 2.34 & 0.0001 & -1.32 & 2.77 & NS \\
\hline
\end{tabular}


the best brace for scoliosis treatment, and it is not yet possible to objectively measure the effects of exercises. In addition the study was done in a everyday clinical setting and not in experimental setting. Another possible limitation is that the treatment management was done by different specialists; according to their personal experience and the specific clinical need of patients. Though all patients included into the study were treated in the same Istitute specialized in the treatment of spine pathologies. All specialists involved have a high grade of experience and work in the same team thus sharing with all the collegues the same strategies for brace treatment. All experts involved into the study strictly follow the actual international guidelines. All these aspect can contribute to a good uniformity. For what the generalizability of the study is concerned, these results can be applied in any super specialized Center on scoliosis conservative management. SOSORT criteria require a good team approach, that should be carefully considered and implemented [11]. Moreover, the SOSORT Guidelines give the indications for personalization of brace treatment according to individual scoliosis patients needs [15]. Finally, the braces used have been well described in the literature [21].

For this study no funding was received, nor there was any conflict of interest issue.

\section{Conclusions}

Bracing in patients with adolescent idiopathic scoliosis who satisfy SRS criteria is effective in reducing progression, and preventing surgery. Combining bracing with exercises according to SOSORT criteria increases treatment efficacy.

\section{Competing interests}

Stefano Negrini has a stock of ISICO (Italian Scientific Spine Institute) of Milan. The other authors do not have any possible conflict of interest.

\section{Authors' contributions \\ All authors participated in data collection and patients' management and treatment. SN conceived the study, and participated in its design and coordination and drafted the manuscript. FZ participated in the design of the study. SN was responsible for conception and design of the study, analysis of data, and drafted the paper. All the authors contributed in interpreting the data, and revised, read and approved the final paper.}

Authors' information

All authors are Medical Doctor. SN is a Professor.

\section{Acknowledgements}

No other contributions, nor funding were received.

\section{Author details}

'Department of Clinical and Experimental Sciences, University of Brescia, Viale Europa 11 Brescia, Italy. ${ }^{2}$ RCCS Don Gnocchi Foundation, Milan, Italy. ${ }^{3}$ ISICO (Italian Scientific Spine Institute), Milan, Italy.

Received: 4 June 2013 Accepted: 16 July 2014

Published: 6 August 2014

\section{References}

1. Weinstein SL, Dolan LA, Wright JG, Dobbs MB: Effects of bracing in adolescents with idiopathic scoliosis. N Engl J Med 2013, 369(16):1512-1521.

2. Negrini S, Minozzi S, Bettany-Saltikov J, Zaina F, Chockalingam N, Grivas TB, Kotwicki T, Maruyama T, Romano M, Vasiliadis ES: Braces for idiopathic scoliosis in adolescents. Cochrane Database Syst Rev 2010, 1:CD006850.

3. Nachemson AL, Peterson LE: Effectiveness of treatment with a brace in girls who have adolescent idiopathic scoliosis. A prospective, controlled study based on data from the Brace Study of the Scoliosis Research Society. J Bone Joint Surg Am 1995, 77(6):815-822.

4. Bunge EM, Habbema JD, de Koning $\mathrm{HJ}$ : A randomised controlled trial on the effectiveness of bracing patients with idiopathic scoliosis: failure to include patients and lessons to be learnt. Eur Spine J 2010, 19(5):747-753.

5. Bunge EM, de Bekker-Grob EW, van Biezen FC, Essink-Bot ML, de Koning HJ: Patients' preferences for scoliosis brace treatment: a discrete choice experiment. Spine (Phila Pa 1976) 2010, 35(1):57-63.

6. Bunge EM, de Koning $\mathrm{HJ}$ : Bracing patients with idiopathic scoliosis: design of the Dutch randomized controlled treatment trial. BMC Musculoskelet Disord 2008, 9:57.

7. Bracing in Adolescent Idiopathic Scoliosis Trial (BrAIST). [http://clinicaltrials gov/ct2/show/NCT00448448]

8. Dolan L, Weinstein S: To BrAIST or not to BrAIST: decisions and characteristics of 1131 patients eligible for the Bracing in Adolescent Idiopathic Scoliosis Trial. Scoliosis 2012, 7(Suppl 1):23.

9. Coillard C, Vachon V, Circo AB, Beausejour M, Rivard CH: Effectiveness of the SpineCor brace based on the new standardized criteria proposed by the scoliosis research society for adolescent idiopathic scoliosis. J Pediatr Orthop 2007, 27(4):375-379.

10. Richards BS, Bernstein RM, D'Amato CR, Thompson GH: Standardization of criteria for adolescent idiopathic scoliosis brace studies: SRS Committee on Bracing and Nonoperative Management. Spine 2005, 30(18):2068-2075. discussion 2076-2067.

11. Negrini S, Grivas TB, Kotwicki T, Rigo M, Zaina F: Guidelines on "Standards of management of idiopathic scoliosis with corrective braces in everyday clinics and in clinical research": SOSORT Consensus 2008. Scoliosis 2009, 4(1):2.

12. Rahman T, Bowen JR, Takemitsu M, Scott C: The association between brace compliance and outcome for patients with idiopathic scoliosis. J Pediatr Orthop 2005, 25(4):420-422.

13. Landauer $\mathrm{F}$, Wimmer $\mathrm{C}$, Behensky $\mathrm{H}$ : Estimating the final outcome of brace treatment for idiopathic thoracic scoliosis at 6-month follow-up. Pediatr Rehabil 2003, 6(3-4):201-207.

14. Katz DE, Durrani AA: Factors that influence outcome in bracing large curves in patients with adolescent idiopathic scoliosis. Spine 2001, 26(21):2354-2361

15. Negrini S, Aulisa AG, Aulisa L, Circo AB, de Mauroy JC, Durmala J, Grivas TB, Knott P, Kotwicki T, Maruyama T, Minozzi S, O'Brien JP, Papadopoulos D, Rigo M, Rivard CH, Romano M, Wynne JH, Villagrasa M, Weiss HR, Zaina F: 2011 SOSORT Guidelines: orthopaedic and rehabilitation treatment of idiopathic scoliosis during growth. Scoliosis 2011, 7(1):3.

16. Gammon SR, Mehlman CT, Chan W, Heifetz J, Durrett G, Wall EJ: A comparison of thoracolumbosacral orthoses and SpineCor treatment of adolescent idiopathic scoliosis patients using the Scoliosis Research Society standardized criteria. J Pediatr Orthop 2010, 30(6):531-538.

17. Aulisa AG, Guzzanti V, Galli M, Perisano C, Falciglia F, Aulisa L: Treatment of thoraco-lumbar curves in adolescent females affected by idiopathic scoliosis with a progressive action short brace (PASB): assessment of results according to the SRS committee on bracing and nonoperative management standardization criteria. Scoliosis 2009, 4:21.

18. Janicki JA, Poe-Kochert C, Armstrong DG, Thompson GH: A comparison of the thoracolumbosacral orthoses and providence orthosis in the treatment of adolescent idiopathic scoliosis: results using the new SRS inclusion and assessment criteria for bracing studies. J Pediatr Orthop 2007, 27(4):369-374.

19. Zaborowska-Sapeta K, Kowalski IM, Kotwicki T, Protasiewicz-Faldowska H, Kiebzak W: Effectiveness of Cheneau brace treatment for idiopathic scoliosis: prospective study in 79 patients followed to skeletal maturity. Scoliosis 2011, 6(1):2.

20. Coillard C, Circo AB, Rivard CH: Effectiveness of the SpineCor brace based on the standardized criteria proposed by the S.R.S. for adolescent idiopathic scoliosis - up to date results. In 6th International Conference on Conservative Management of Spinal Deformites: 2009. Lyon; 2009:saa15. 
21. Negrini S, Marchini G, Tessadri F: "Brace technology" thematic series - The Sforzesco and Sibilla braces, and the SPoRT (Symmetric, Patient oriented, Rigid, Three-dimensional, active) concept. Scoliosis 2011, 6(1):8.

22. de Mauroy JC, Lecante C, Barral F: "Brace Technology" Thematic Series - The Lyon approach to the conservative treatment of scoliosis. Scoliosis 2011, 6(1):4.

23. SpineCor System. [http://www.srs.org/professionals/education_materials/ SRS_bracing_manual/section13.pdf]

24. Donzelli S, Zaina F, Negrini S: It is possible to make patients use braces the hours prescribed: first results from the thermobrace clinical everyday usage. Scoliosis 2012, 7(Suppl 1):29.

25. Negrini S, Negrini F, Fusco C, Zaina F: Idiopathic scoliosis patients with curves more than 45 Cobb degrees refusing surgery can be effectively treated through bracing with curve improvements. Spine J 2011, 11(5):369-380

26. Negrini S: The Evidence-Based ISICO Approach to Spinal Deformities. 1st edition. Milan, Boston: ISICO; 2007.

27. Zaina F, Negrini S, Atanasio S, Fusco C, Romano M, Negrini A: Specific exercises performed in the period of brace weaning can avoid loss of correction in Adolescent Idiopathic Scoliosis (AIS) patients: Winner of SOSORT's 2008 Award for Best Clinical Paper. Scoliosis 2009, 4(1):8.

28. Negrini S, Negrini A, Romano M, Verzini N, Parzini S: A controlled prospective study on the efficacy of SEAS.02 exercises in preparation to bracing for idiopathic scoliosis. Stud Health Technol Inform 2006, 123:519-522.

29. Kotwicki T, Durmala J, Czaprowski D, Glowacki M, Kolban M, Snela S, Sliwinski Z, Kowalski IM: Conservative management of idiopathic scoliosis-guidelines based on SOSORT 2006 Consensus. Ortop Traumatol Rehabil 2009, 11(5):379-395.

30. Kotwicki T: Improved accuracy in Risser sign grading with lateral spinal radiography. Eur Spine J 2008, 17(12):1676-1685.

31. Negrini S, Atanasio S, Fusco C, Zaina F: Effectiveness of complete conservative treatment for adolescent idiopathic scoliosis (bracing and exercises) based on SOSORT management criteria: results according to the SRS criteria for bracing studies - SOSORT Award 2009 Winner. Scoliosis 2009, 4:19.

32. Don R, Capodaglio P, Cimolin V, Benedetti MG, D'Osualdo F, Frigo C, Vismara L, Negrini S: Instrumental measures of spinal function: is it worth? A state-of-the art from a clinical perspective. Eur J Phys Rehabil Med 2012, 48(2):255-273.

33. Zaina F, Donzelli S, Lusini M, Negrini S: How to measure kyphosis in everyday clinical practice: a reliability study on different methods. Stud Health Technol Inform 2012, 176:264-267.

34. Rigo M, Reiter $\mathrm{C}$, Weiss $\mathrm{H}$ : Effect of conservative management on the prevalence of surgery in patients with adolescent idiopathic scoliosis. Pediatr Rehabil 2003, 6:209-214

35. Maruyama T, Kitagawa T, Takeshita K, Mochizuki K, Nakamura K: Conservative treatment for adolescent idiopathic scoliosis: can it reduce the incidence of surgical treatment? Pediatr Rehabil 2003, 6(3-4):215-219.

36. Negrini S, Atanasio S, Zaina F, Romano M, Parzini S, Negrini A: End-growth results of bracing and exercises for adolescent idiopathic scoliosis. Prospective worst-case analysis. Stud Health Technol Inform 2008, 135:395-408.

37. Dolan LA, Weinstein SL: Surgical rates after observation and bracing for adolescent idiopathic scoliosis: an evidence-based review. Spine 2007, 32(19 Suppl):S91-S100.

38. Negrini S, Grivas TB: Introduction to the "Scoliosis" Journal Brace Technology Thematic Series: increasing existing knowledge and promoting future developments. Scoliosis 2010, 5(1):2.

39. Lange JE, Steen $\mathrm{H}$, Gunderson R, Brox Jl: Long-term results after Boston brace treatment in late-onset juvenile and adolescent idiopathic scoliosis. Scoliosis 2011, 16:18.

40. Brox Jl, Lange JE, Gunderson RB, Steen H: Good brace compliance reduced curve progression and surgical rates in patients with idiopathic scoliosis. Eur Spine J 2012, 21(10):1957-1963.

doi:10.1186/1471-2474-15-263

Cite this article as: Negrini et al:: The effectiveness of combined bracing and exercise in adolescent idiopathic scoliosis based on SRS and SOSORT criteria: a prospective study. BMC Musculoskeletal Disorders 2014 15:263.

\section{Submit your next manuscript to BioMed Central and take full advantage of:}

- Convenient online submission

- Thorough peer review

- No space constraints or color figure charges

- Immediate publication on acceptance

- Inclusion in PubMed, CAS, Scopus and Google Scholar

- Research which is freely available for redistribution 